\title{
NADPH oxidase 4 and its role in the cardiovascular system
}

\author{
Stephen P Gray, Ajay M Shah and Ioannis Smyrnias \\ School of Cardiovascular Medicine \& Sciences, King's College London British Heart Foundation Centre, London, UK
}

Correspondence should be addressed to I Smyrnias: ioannis.smyrnias@kcl.ac.uk

\begin{abstract}
The heart relies on complex mechanisms that provide adequate myocardial oxygen supply Key Words in order to maintain its contractile function. At the cellular level, oxygen undergoes one electron reduction to superoxide through the action of different types of oxidases (e.g. xanthine oxidases, uncoupled nitric oxide synthases, NADPH oxidases or NOX). Locally generated oxygen-derived reactive species (ROS) are involved in various signaling pathways

- NOX4

- heart

- ROS

- vasculature including cardiac adaptation to different types of physiological and pathophysiological stresses (e.g. hypoxia or overload). The specific effects of ROS and their regulation by oxidases are dependent on the amount of ROS generated and their specific subcellular localization. The NOX family of NADPH oxidases is a main source of ROS in the heart. Seven distinct Nox isoforms (NOX1-NOX5 and DUOX1 and 2) have been identified, of which NOX1, 2, 4 and 5 have been characterized in the cardiovascular system. For the purposes of this review, we will focus on the effects of NADPH oxidase 4 (NOX4) in the heart.
\end{abstract}

\section{NOX4 variants, activity and localization}

NOX4 is a dual heme-containing transmembrane oxidoreductase that spans the membrane six times. NOX4 exists as a heterodimer bound to a p22phox subunit, which is necessary for its activity (1). In contrast to other NOX isoforms, NOX4 does not require any cytosolic regulatory subunit for its activity and is constitutively active with its regulation being a direct consequence of its abundance and intracellular localization (Table 1 for activity, regulation and expression of the main NOXs in the cardiovascular system). Under physiological conditions, NOX4 was first identified and has its highest levels of expression in kidney proximal tubular cells (2), but is also expressed in many other cell types, including cardiomyocytes, endothelial and smooth muscle cells, osteoclasts, epithelial cells and hemopoietic stem cells; albeit at lower levels. Interestingly, NOX4 is encoded by a gene which contains 34 introns and is transcribed into 16 spliced variants, of which at least four generate proteins (NOX4B-E) (3). In particular, NOX4D is the only variant that has been found to be functionally active in terms of ROS generation, despite lacking putative transmembrane regions as it retains the NADPH- and FAD-binding domains required for electron transfer activity. Hence, NOX4D can modulate redoxsensitive transcriptional regulation downstream of ERK1/2 phosphorylation and induces nuclear DNA damage (4). However, further studies are required to delineate the pathophysiological effects of these NOX4 variants. Adding to NOX4 variation, using the standard human NOX4 gene sequence for comparison, there have been more than 2300 SNP sites found in the genomic DNA region of NOX4, and 45 SNPs in the gene-coding region. These SNPs may affect gene replication, transcription and even NOX4 function that may determine the progress and/or development of disease. For instance, polymorphism of 
Table 1 The main NOXs in the cardiovascular system.

\begin{tabular}{|c|c|c|}
\hline & Activity & $\begin{array}{l}\text { Regulatory subunits/ } \\
\text { requirement for p22phox }\end{array}$ \\
\hline NOX1 & Inducible & NOX01, NOXA1, Rac/yes \\
\hline NOX2 & Inducible & P47phox, p67phox, p40phox, Rac/yes \\
\hline NOX4 & Constitutively active & None/yes \\
\hline NOX5 & Low constitutive activity & None/no \\
\hline
\end{tabular}

rs1836882 in the NOX4 gene modulates associations between dietary caloric intake and ROS levels in peripheral blood mononuclear cells (5). In the cardiovascular system, the NOX4 rs11018628 polymorphism has been associated with a decreased risk and better short-term recovery of ischemic stroke (6). More studies are needed to better understand connections between polymorphisms of NOX4 in different populations and disease-related NOX4 variants.

In the cardiovascular system, several conditions, such as pressure overload, hypoxia and inflammation lead to increased NOX4 expression, significantly impacting cellular function. Adding to its distinct characteristics over other NOXs, NOX4 primarily produces hydrogen peroxide rather than superoxide due to the presence of an E-loop in its structure that promotes the rapid dismutation of superoxide before it leaves the enzyme (7). In addition to the type of ROS generated by NOX4, its subcellular localization also influences various NOX4 functions, including enzyme activity and the activation of distinct downstream signaling pathways $(8,9)$. However, the exact location of NOX4 remains largely debated, with reports positioning the enzyme in the endoplasmic reticulum, mitochondria, plasma membrane and nucleus $(10,11)$. The reasons for these disparities may reflect the cell-specific differences in the functions of NOX4 in the different cell types studied, the fact that NOX4 localization might be transitory based on its interactions with certain targets (12) and/or the quality of research tools and approaches employed.

\section{NOX4 in the stressed heart}

The role of NOX4 in the heart has been characterized in various cardiac disease models with the use of systemic

\section{Cell expression}

Regulation by

Post-translational Vascular smooth muscle, modification of regulatory endothelial cells subunits

modification of regulatory subunits

Poldip2 and

transcriptional regulation

$\mathrm{Ca}^{2+}$
Cardiomyocytes, endothelial cells, fibroblasts, vascular smooth muscle cells, inflammatory cells Cardiomyocytes, endothelial cells, fibroblasts, vascular smooth muscle cells

Vascular smooth muscle and endothelial cells (absent in rodents) and/or cardiomyocyte-specific NOX4 overexpression or deletion animal models. A summary of the literature is included in Table 2. Several studies report a protective role of NOX4 in models of cardiac hypertrophy and against cardiac remodeling under conditions of stress. The functional benefits of increased NOX4 levels in the pressure-overloaded heart were first identified by Zhang et al. when they employed loss- and gain-of-function NOX4 mouse models and reported that, following abdominal aortic banding in mice, NOX4 exerts its protective effects through a mechanism involving paracrine enhancement of capillary density (13). Contrasting observations were reported by the Sadoshima laboratory when they reported the detrimental effects of NOX 4 in the overloaded heart due to increased mitochondrial ROS production and damage (14). While these differences may be attributed to the type and severity of overload studied and means via which NOX4 levels were manipulated, the protective effects of NOX 4 have been since corroborated in cardiomyocyteand endothelial-specific NOX4-null mice, where transaortic constriction was associated with more severe cardiac function and remodeling in the NOX4-deficient mice (15). Further adding to the protective roles of NOX4 in cardiomyocytes under stress, studies have described the reliance of NOX4 on the antioxidant transcription factor nuclear factor erythroid 2-related factor 2 (NRF2) $(16,17)$, as well as the NOX4-derived ROS production in the ER and subsequent activation of autophagy, which ensures cell survival during energy deprivation (18).

Whereas the protective role of NOX 4 in the chronically overloaded heart is well established, contrasting results have been reported on the role of NOX4 in ischemia/ reperfusion (IR) injury. Braunersreuther et al. have reported that NOX4 deletion does not influence myocardial reperfusion injury while demonstrating the activation of cardioprotective pathways following 


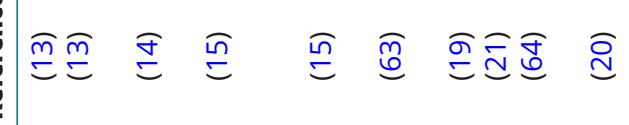

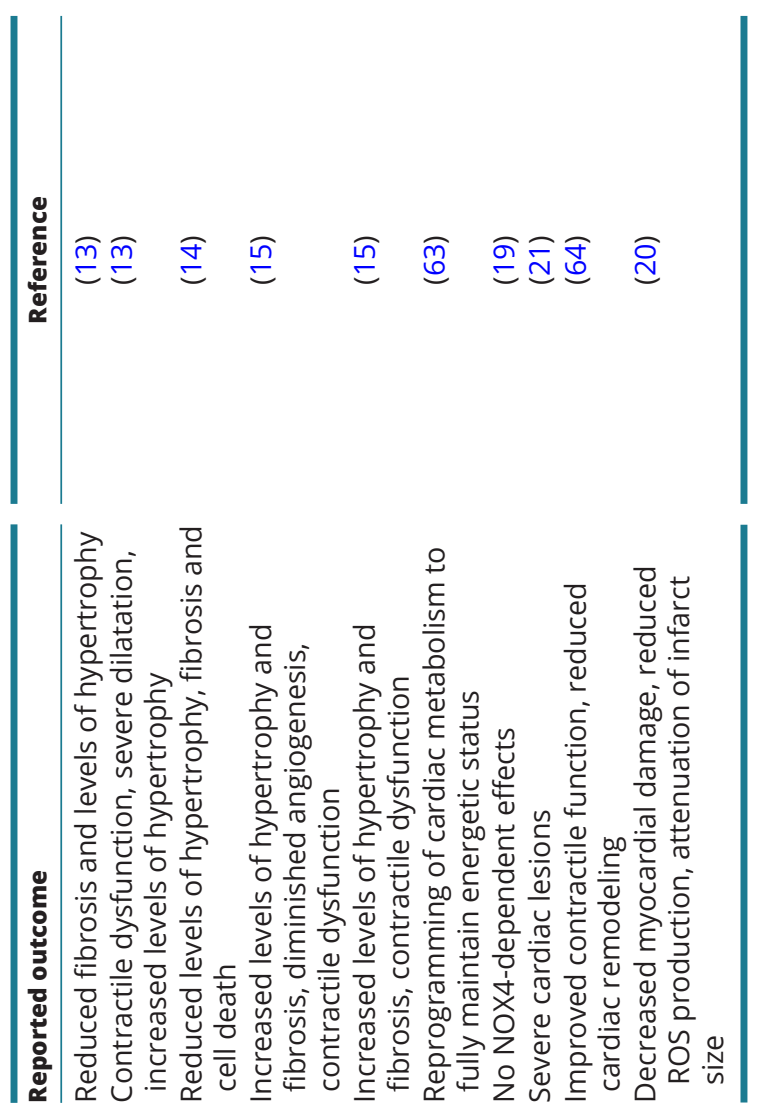

ablation of NOX1 and NOX2 (19). In another study, Matsusima et al. demonstrated a decrease in myocardial damage following IR in cardiac-specific NOX4-deficient mice, which was associated with reduced ROS production and an attenuation of the infarct size, suggesting that NOX4 actually mediates IR injury (20). However, myocardial injury was exacerbated in the NOK2-/NOX4deficient mice, suggesting that a certain amount of ROS produced by either NOX2 or NOX4 is necessary for protection against IR injury. Moreover, a study by Santos et al. shows extensive data on a NOX4-regulated pathway involving inactivation of the protein phosphatase 1 (PP1) and sustained eIF $2 \alpha$ phosphorylation, which regulates the transcription factor ATF4 and enhances cell survival in heart IR injury. This novel redox signaling pathway involves an interaction between NOX4, growth arrest and DNA damage-inducible 34 (GADD34) to inactivate the protein phosphatase 1 (PP1) metal center and sustain eIF $2 \alpha$ phosphorylation, eventually protecting the heart under stress (21). Further studies are required to delineate some of these discrepancies on the exact role of NOX4 during IR injury in the heart.

\section{NOX4 and the vasculature}

A summary of the literature describing the role of NOX4 in vascular disease models is included in Table 3. Most pathologies of the vasculature start with endothelial dysfunction (ED) increasing the likelihood of developing hypertension $(22,23)$. NOX 4 has been demonstrated to be an important vasodilator and can act as an endotheliumderived hyperpolarizing factor $(24,25) . \mathrm{H}_{2} \mathrm{O}_{2}$ has been shown to increase endothelial NOS expression and activity (26), enhancing NO production (27). A role for NOX4 in hypertension is contentious and has not yet been conclusively determined $(28,29)$. Endothelial cell (EC)-specific overexpression of NOX4 enhanced agonistmediated vasodilatation resulting in a decrease in basal blood pressure (BP) (30). This effect was mediated through the vasodilatory actions of $\mathrm{H}_{2} \mathrm{O}_{2}$ and not by increased NO bioavailability (31). In agreement, Paravicini et al. (32) showed that NOX4 expression in basilar arteries was associated with enhanced vasodilatation in response to $\mathrm{H}_{2} \mathrm{O}_{2}$-mediated activation of $\mathrm{BK}(\mathrm{Ca})$ channels. Conversely, a number of studies have reported no change in BP (33, $34,35,36)$. Such is the recent study by Bouabout et al. (37), which demonstrated no change in BP at baseline in NOX4-deficient mice, but a protection in Ang-II mediated arterial and pulse pressure increases. Taken together, 
Table 3 NOX4 in vascular disease models.

\begin{tabular}{|c|c|}
\hline $\begin{array}{l}\text { NOX4 modification } \\
\text { (vascular disease models) }\end{array}$ & Disease model \\
\hline Overexpression & Endothelial Dysfunction \\
\hline Global deletion & Hypertension \\
\hline Global deletion & Endothelial dysfunction \\
\hline Global deletion & Atherosclerosis \\
\hline Global deletion & Ischemia/reperfusion and Stroke \\
\hline Global deletion & Atherosclerosis \\
\hline
\end{tabular}

these findings suggest that while NOX4 has been demonstrated to be involved in the regulation of hypertension, its effects could be cell and disease specific.

Atherosclerosis development involves multiple cell types, which all express NOX4 at basal levels and as such it is expected that NOX4 plays a role; albeit several studies have suggested both an athero-protective (30, 38, $39,40)$ and a deleterious role $(41,42,43,44,45)$. The induction of growth factors and cytokines in the vessel have been shown to be regulated by NOX4 $(40,46$, 47) and that NOX4 has been implicated in neointima formation after vascular injury. Specifically, knockdown of NOX4 in Zucker rats reduced SERCA oxidation and inhibited the development of the neointima in carotid injury (14). Moreover, oxidized LDL stimulates NOX4 expression in macrophages, a process that leads to necrotic core formation within lesions (48). Furthermore, NOX4 has been linked to smooth muscle cell (SMC) migration and proliferation, which are essential steps in the development of atherosclerosis $(42,49)$. Xu et al. (43) reported that NOX4 expression was increased in aged atherosclerotic plaques, specifically in the SMC of unstable plaques, through an increase in SMC senescence and apoptosis (43), an important step in the development of unstable lesions. It has also been demonstrated that in the setting of diabetes, NOX4 deletion results in a dedifferentiation of the SMC and increased proliferation (49). Additionally, STZ-diabetic NOX4-/ApoE-deficient mice have no change in atherosclerosis development after 10 weeks (34); however, after 20 weeks of diabetes, there was a significant elevation in atherosclerotic development through increased SMC proliferation (35). Furthermore, EC-specific overexpression of the human NOX4 dominant negative $\mathrm{P} 437 \mathrm{H}$ mutant led to an acceleration in atherosclerosis development and a cell-specific decline in NOX4 expression in the EC vs SMC of STZ-diabetic mouse vessels (50). These findings indicate that NOX4 in the setting of atherosclerosis appears to work in a
Reference

$(30,38)$ time-/cell-/disease-specific manner and that overall NOX4 appears to play an athero-protective role.

Transient or sustained ischemia can lead to infarcts and stroke within the cerebral vasculature. Similar to the reports in the pressure-overloaded heart, NOX4 has been linked to the pathophysiology of stroke, since its expression and activity is increased as a consequence of hypoxia (51, $52)$. NOX4 is upregulated in the cortical neurons within $24 \mathrm{~h}$ of middle cerebral artery occlusion (51). Transient upregulation of NOX4 in the cortex is also observed after endothelin-induced stroke (53). In an extensive study conducted by Kleinschnitz et al. (39), NOX4-deficient mice had less oxidative stress, less blood-brain barrier leakage and less neuronal apoptosis after either transient occlusion of the middle cerebral artery or after permanent stroke induced by cortical photothrombosis. Importantly, post-stroke treatment with the putative NOX inhibitor VAS2870 improved recovery, suggesting that NOX4 may be a viable therapeutic target in the setting of stroke (39). This notion has gained further support in a recent study, which identified an increase in infarct size after middle cerebral artery occlusion in addition to a reduction in endothelial-derived eNOS when NOX4 oxidase was overexpressed in EC (54). The contrasting findings in the setting of stroke compared to the setting of atherosclerosis highlight that NOX4 can play both a detrimental and protective role in disease development and that this may largely depend on the specific nature of the vessel, that being macrovascular or microvascular. This highlights the need for further research into the role of NOX4 in other vascular beds, before using blanket NOX4 inhibitors to modulate disease development.

\section{NOX4-mediated regulation of transcription factors in the heart}

Several studies have reported the ability of NOX4 to regulate distinct signaling pathways and cellular functions 


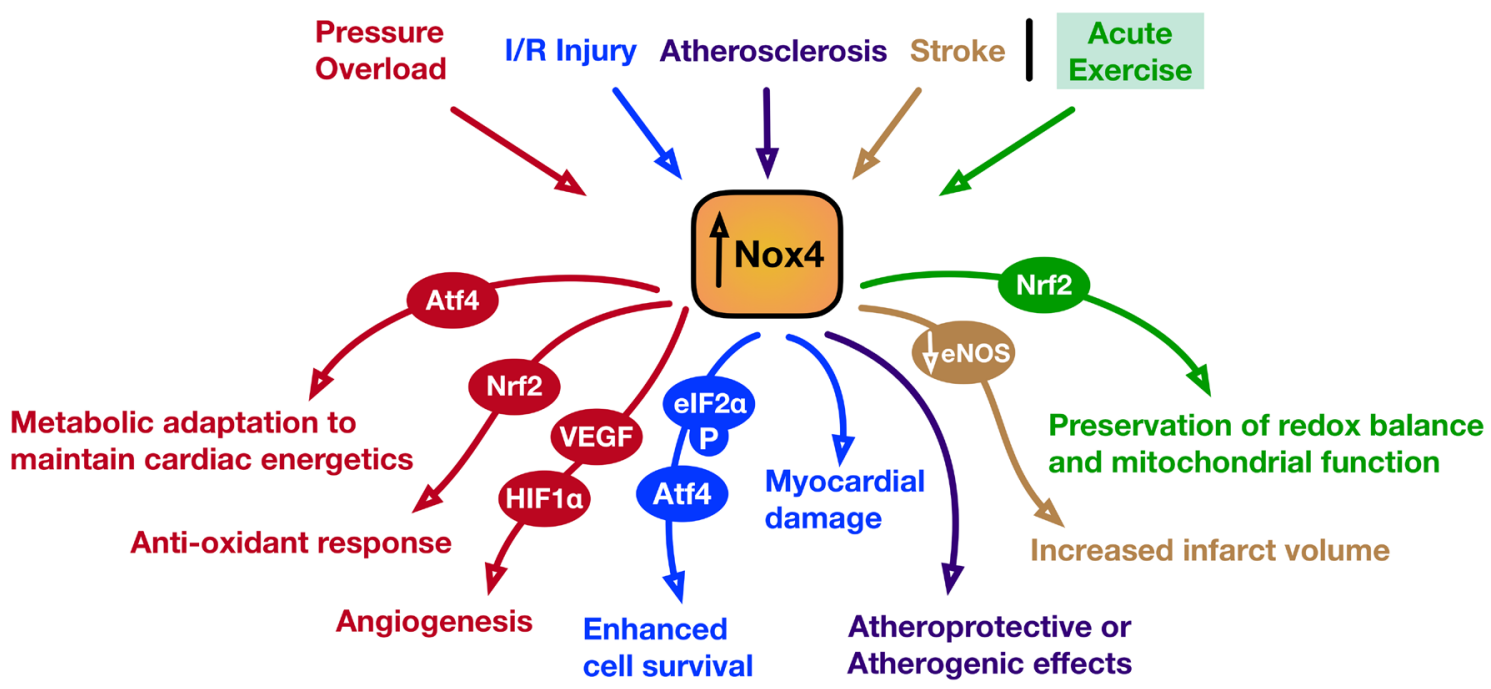

\section{Figure 1}

The pathophysiological and physiological effects of NOX4 under various conditions of cardiovascular stress. Summary of the key signaling events that have been identified to be regulated by NOX4 that are engaged downstream of various pathological (pressure overload; red, l/R injury; blue, atherosclerosis; purple, stroke; brown) or physiological (acute exercise; green) cardiovascular stresses.

(e.g., proliferation (55), apoptosis (56), angiogenesis (13) and more) based on its levels of expression, intracellular localization and the cell type studied. For instance, among others NOX4 has been shown to activate the kinases p38, JNK, ERK1/2 and Akt in both stimulated and naïve cells $(57,58,59)$. In the cardiovascular system, NOX4 has been shown to convey several of its actions via interaction with different transcription factors such as NRF2, HIF1a and ATF4. NRF2 is a pleiotropic transcription factor primarily acting as a central regulator of an antioxidant cytoprotective gene program that can be activated in cardiomyocytes during acute neurohumoural stress or in the overloaded heart in vivo. Overexpression of NOX4 in vivo has been shown to mediate the expression of antioxidant and detoxifying genes regulated by NRF2, as well as an NRF2-dependent elevation of glutathione and biosynthetic and recycling enzymes, suggesting a role for NOX4 in the regulation of glutathione redox in the heart (16). Furthermore, upregulation of NOX4 in the stressed heart in vivo specifically activates NRF2 and its downstream antioxidant signaling cascade, which serves to limit oxidative stress, mitochondrial DNA damage and cardiomyocyte death (17). As recently demonstrated, NRF2 also contributes to the physiological role of NOX4 in the heart as an activator of NRF2 in order to support normal physical exercise (60). Specifically, the increased levels of NOX4 observed following acute exercise result in the concomitant activation of the NRF2 transcription factor and its antioxidant target genes for optimal increments in heart performance during exercise. The pairing between
NOX4 and NRF2 triggers an adaptive response to maintain redox state and support mitochondrial and, hence, contractile function in the exercised heart.

The cardioprotective effects of NOX4 have also been attributed to regulation of the hypoxia-induced HIF1a. The transcription factor Hif1a and VEGF signaling mediate cardiac remodeling and hypertrophy and promote angiogenesis to protect the stressed heart $(61,62)$. Indeed, NOX4 is protective against cardiac decompensation during hemodynamic overload via the activation of HIF1a, possibly due to inhibition of prolyl hydroxylases (PHDs) and release of VEGF from cardiomyocytes and/or ECs (15). As a result of the actions of NOX 4 myocardial capillary density is preserved in the pressure-overloaded heart.

Finally, studies have demonstrated the interplay between NOX4 and the ATF4 transcription factor in the diseased heart. Autophagy is an essential survival mechanism in the energy-deprived heart. Indeed, activated NOX4 and subsequent generation of ROS promote autophagy in response to energy stress (e.g., fasting) through activation of the PKR-like ER kinase (PERK) pathway by suppression of prolyl hydroxylase 4 (PHD4) (18). Moreover, in the pressure-overloaded heart, hypertrophic remodeling includes a switch in the preferred energy substrate from fatty acids to glucose. The upregulation of NOX4 levels in the overloaded heart reprograms cardiac substrate metabolism in order to maintain cardiac energetics under conditions of stress. Nabeebaccus et al. recently reported a NOX4- and ATF4dependent upregulation of the hexosamine biosynthetic 
pathway, which enhances fatty acid utilization via the attachment of O-linked $\mathrm{N}$-acetylglucosamine (O-GlcNAcylation) to the fatty acid transporter CD36 (63). This is a novel identification of a NOX4-dependent coordinated reprogramming of cardiac fatty acid and glucose metabolism, demonstrating the optimal compartmentalization of glucose as an adaptive pathway in the hemodynamically overloaded heart.

\section{Conclusion}

The diverse outcomes of NOX4 activation in the cardiovascular system (Fig. 1) are one of the reasons why non-specific, antioxidant approaches have failed to demonstrate any positive outcomes in heart disease. The interplay between redox pools with detrimental and/or beneficial effects exemplifies the requirement for the identification of specific targets for therapeutic manipulation (i.e. activation of NOX4-regulated pathways). Better understanding of the ROS-regulated signaling pathways and data on humans will determine the potential for clinical translation.

\section{Declaration of interest}

The authors declare that there is no conflict of interest that could be perceived as prejudicing the impartiality of this review.

\section{Funding}

This work was supported by the British Heart Foundation (grant numbers $\mathrm{PG} / 16 / 30 / 32129$, RG/13/11/30384, and FS/14/77/30913); in part by the Department of Health via a National Institute for Health Research (NIHR) Biomedical Research Centre award to Guy's \& St Thomas' NHS Foundation Trust in partnership with King's College London and King's College Hospital NHS Foundation Trust and a Fondation Leducq Transatlantic Network of Excellence.

\section{Acknowledgements}

The authors are very grateful to all current and past members of the Shah laboratory whose work has been cited in this review.

\section{References}

1 Bedard K \& Krause KH. The NOX family of ROS-generating NADPH oxidases: physiology and pathophysiology. Physiological Reviews 2007 87 245-313. (https://doi.org/10.1152/physrev.00044.2005)

2 Geiszt M, Kopp JB, Várnai P \& Leto TL. Identification of renox, an NAD(P)H oxidase in kidney. PNAS 200097 8010-8014. (https://doi. org/10.1073/pnas.130135897)
3 Goyal P, Weissmann N, Rose F, Grimminger F, Schäfers HJ, Seeger W \& Hänze J. Identification of novel Nox4 splice variants with impact on ROS levels in A549 cells. Biochemical and Biophysical Research Communications 2005329 32-39. (https://doi.org/10.1016/j. bbrc.2005.01.089)

4 Anilkumar N, San Jose G, Sawyer I, Santos CX, Sand C, Brewer AC, Warren D \& Shah AM. A 28-kDa splice variant of NADPH oxidase-4 is nuclear-localized and involved in redox signaling in vascular cells. Arteriosclerosis, Thrombosis, and Vascular Biology 201333 e104-e112. (https://doi.org/10.1161/ATVBAHA.112.300956)

5 Liu Q, Li H, Wang N, Chen H, Jin Q, Zhang R, Wang J \& Chen Y. Polymorphism of rs1836882 in NOX4 gene modifies associations between dietary caloric intake and ROS levels in peripheral blood mononuclear cells. PLOS ONE 20138 e85660. (https://doi. org/10.1371/journal.pone.0085660)

6 He W, Wang Q, Gu L, Zhong L \& Liu D. NOX4 rs11018628 polymorphism associates with a decreased risk and better short-term recovery of ischemic stroke. Experimental and Therapeutic Medicine 201816 5258-5264. (https://doi.org/10.3892/etm.2018.6874)

7 Takac I, Schröder K, Zhang L, Lardy B, Anilkumar N, Lambeth JD, Shah AM, Morel F \& Brandes RP. The E-loop is involved in hydrogen peroxide formation by the NADPH oxidase Nox4. Journal of Biological Chemistry 2011286 13304-13313. (https://doi.org/10.1074/jbc. M110.192138)

8 Hilenski LL, Clempus RE, Quinn MT, Lambeth JD \& Griendling KK. Distinct subcellular localizations of Nox1 and Nox4 in vascular smooth muscle cells. Arteriosclerosis, Thrombosis, and Vascular Biology 200424 677-683. (https://doi.org/10.1161/01. ATV.0000112024.13727.2c)

9 Weyemi U, Caillou B, Talbot M, Ameziane-El-Hassani R, Lacroix L, Lagent-Chevallier O, Al Ghuzlan A, Roos D, Bidart JM, Virion A, et al. Intracellular expression of reactive oxygen species-generating NADPH oxidase NOX4 in normal and cancer thyroid tissues. Endocrine-Related Cancer 201017 27-37. (https://doi.org/10.1677/ ERC-09-0175)

10 Prior KK, Wittig I, Leisegang MS, Groenendyk J, Weissmann N, Michalak M, Jansen-Dürr P, Shah AM \& Brandes RP. The endoplasmic reticulum chaperone calnexin is a NADPH oxidase NOX4 interacting protein. Journal of Biological Chemistry 2016291 7045-7059. (https:// doi.org/10.1074/jbc.M115.710772)

11 Block K, Gorin Y \& Abboud HE. Subcellular localization of Nox4 and regulation in diabetes. PNAS 2009106 14385-14390. (https://doi. org/10.1073/pnas.0906805106)

12 Lyle AN, Deshpande NN, Taniyama Y, Seidel-Rogol B, Pounkova L, Du P, Papaharalambus C, Lassègue B \& Griendling KK. Poldip2, a novel regulator of Nox4 and cytoskeletal integrity in vascular smooth muscle cells. Circulation Research 2009105 249-259. (https:// doi.org/10.1161/CIRCRESAHA.109.193722)

13 Zhang M, Brewer AC, Schröder K, Santos CX, Grieve DJ, Wang M, Anilkumar N, Yu B, Dong X, Walker SJ, et al. NADPH oxidase-4 mediates protection against chronic load-induced stress in mouse hearts by enhancing angiogenesis. PNAS 2010107 18121-18126. (https://doi.org/10.1073/pnas.1009700107)

14 Kuroda J, Ago T, Matsushima S, Zhai P, Schneider MD \& Sadoshima J. NADPH oxidase 4 (Nox4) is a major source of oxidative stress in the failing heart. PNAS 2010107 15565-15570. (https://doi.org/10.1073/ pnas.1002178107)

15 Zhang M, Mongue-Din H, Martin D, Catibog N, Smyrnias I, Zhang X, Yu B, Wang M, Brandes RP, Schröder K, et al. Both cardiomyocyte and endothelial cell Nox4 mediate protection against hemodynamic overload-induced remodelling. Cardiovascular Research 2018114 401-408. (https://doi.org/10.1093/cvr/cvx204)

16 Brewer AC, Murray TVA, Arno M, Zhang M, Anilkumar NP, Mann GE \& Shah AM. Nox4 regulates Nrf2 and glutathione redox in cardiomyocytes in vivo. Free Radical Biology and Medicine 201151 205-215. (https://doi.org/10.1016/j.freeradbiomed.2011.04.022) 
17 Smyrnias I, Zhang X, Zhang M, Murray TVA, Brandes RP, Schröder K, Brewer AC \& Shah AM. Nicotinamide adenine dinucleotide phosphate oxidase-4-dependent upregulation of nuclear factor erythroid-derived 2-like 2 protects the heart during chronic pressure overload. Hypertension 201565 547-553. (https://doi.org/10.1161/ HYPERTENSIONAHA.114.04208)

18 Sciarretta S, Zhai P, Shao D, Zablocki D, Nagarajan N, Terada LS, Volpe M \& Sadoshima J. Activation of NADPH oxidase 4 in the endoplasmic reticulum promotes cardiomyocyte autophagy and survival during energy stress through the protein kinase RNA-activated-like endoplasmic reticulum kinase/eukaryotic initiation factor 2alpha/activating transcription factor 4 pathway. Circulation Research 2013113 1253-1264. (https://doi.org/10.1161/ CIRCRESAHA.113.301787)

19 Braunersreuther V, Montecucco F, Asrih M, Pelli G, Galan K, Frias M, Burger F, Quinderé AL, Montessuit C, Krause $\mathrm{KH}$, et al. Role of NADPH oxidase isoforms NOX1, NOX2 and NOX4 in myocardial ischemia/reperfusion injury. Journal of Molecular and Cellular Cardiology 201364 99-107. (https://doi.org/10.1016/j. yjmcc.2013.09.007)

20 Matsushima S, Kuroda J, Ago T, Zhai P, Ikeda Y, Oka S, Fong G, Tian R \& Sadoshima J. Broad suppression of NADPH oxidase activity exacerbates ischemia/reperfusion injury through inadvertent downregulation of hypoxia-inducible factor-1alpha and upregulation of peroxisome proliferator-activated receptor-alpha. Circulation Research 2013112 1135-1149. (https://doi.org/10.1161/ CIRCRESAHA.111.300171)

21 Santos CX, Hafstad AD, Beretta M, Zhang M, Molenaar C, Kopec J, Fotinou D, Murray TV, Cobb AM, Martin D, et al. Targeted redox inhibition of protein phosphatase 1 by Nox 4 regulates eIF2alphamediated stress signaling. EMBO Journal 201635 319-334. (https:// doi.org/10.15252/embj.201592394)

22 de Dios ST, Sobey CG \& Drummond GR. Oxidative stress and endothelial dysfunction. In Endothelial Dysfunction and Inflammation. Progress in Inflammation Research. Eds S Dauphinee \& A Karsan, pp37. Basel, Switzerland: Springer, 2010. (https://doi.org/10.1007/978-30346-0168-9_3)

23 Endemann DH \& Schiffrin EL. Endothelial dysfunction. Journal of the American Society of Nephrology 200415 1983-1992. (https://doi. org/10.1097/01.ASN.0000132474.50966.DA)

24 Shimokawa $\mathrm{H} \&$ Morikawa K. Hydrogen peroxide is an endotheliumderived hyperpolarizing factor in animals and humans. Journal of Molecular and Cellular Cardiology 200539 725-732. (https://doi. org/10.1016/j.yjmcc.2005.07.007)

25 Larsen BT, Bubolz AH, Mendoza SA, Pritchard KA \& Gutterman DD. Bradykinin-induced dilation of human coronary arterioles requires NADPH oxidase-derived reactive oxygen species. Arteriosclerosis, Thrombosis, and Vascular Biology 200929 739-745. (https://doi. org/10.1161/ATVBAHA.108.169367)

26 Thomas SR, Chen K \& Keaney Jr JF. Hydrogen peroxide activates endothelial nitric-oxide synthase through coordinated phosphorylation and dephosphorylation via a phosphoinositide 3-kinase-dependent signaling pathway. Journal of Biological Chemistry 2002277 6017-6024. (https://doi.org/10.1074/jbc.M109107200)

27 Burgoyne JR, Madhani M, Cuello F, Charles RL, Brennan JP, Schroder E, Browning DD \& Eaton P. Cysteine redox sensor in PKGIa enables oxidant-induced activation. Science 2007317 1393-1397. (https://doi.org/10.1126/science.1144318)

28 Wingler K, Wünsch S, Kreutz R, Rothermund L, Paul M \& Schmidt HH. Upregulation of the vascular NAD(P)H-oxidase isoforms Nox 1 and Nox 4 by the renin-angiotensin system in vitro and in vivo. Free Radical Biology and Medicine 200131 1456-1464. (https://doi. org/10.1016/S0891-5849(01)00727-4)

29 Akasaki T, Ohya Y, Kuroda J, Eto K, Abe I, Sumimoto H \& Iida M. Increased expression of gp91phox homologues of $\mathrm{NAD}(\mathrm{P}) \mathrm{H}$ oxidase in the aortic media during chronic hypertension: involvement of the renin-angiotensin system. Hypertension Research 200629 813-820. (https://doi.org/10.1291/hypres.29.813)

30 Ray R, Murdoch CE, Wang M, Santos CX, Zhang M, Alom-Ruiz S, Anilkumar N, Ouattara A, Cave AC, Walker SJ, et al. Endothelial Nox4 NADPH oxidase enhances vasodilatation and reduces blood pressure in vivo. Arteriosclerosis, Thrombosis, and Vascular Biology 2011 31 1368-1376. (https://doi.org/10.1161/ATVBAHA.110.219238)

31 Sedeek M, Callera G, Montezano A, Gutsol A, Heitz F, Szyndralewiez C, Page P, Kennedy CR, Burns KD, Touyz RM, et al. Critical role of Nox4-based NADPH oxidase in glucose-induced oxidative stress in the kidney: implications in type 2 diabetic nephropathy. American Journal of Physiology: Renal Physiology 2010 299 F1348-F1358. (https://doi.org/10.1152/ajprenal.00028.2010)

32 Paravicini TM, Chrissobolis S, Drummond GR \& Sobey CG. Increased NADPH-oxidase activity and Nox4 expression during chronic hypertension is associated with enhanced cerebral vasodilatation to NADPH in vivo. Stroke 200435 584-589. (https://doi.org/10.1161/01. STR.0000112974.37028.58)

33 Schmidt HH, Wingler K, Kleinschnitz C \& Dusting G. NOX4 is a Janus-faced reactive oxygen species generating NADPH oxidase. Circulation Research 2012111 e15-e16; author reply e17-e18. (https://doi.org/10.1161/CIRCRESAHA.112.271957)

34 Gray SP, Di Marco E, Okabe J, Szyndralewiez C, Heitz F, Montezano AC, de Haan JB, Koulis C, El-Osta A, Andrews KL, et al. NADPH oxidase 1 plays a key role in diabetes mellitus-accelerated atherosclerosis. Circulation 2013127 1888-1902. (https://doi. org/10.1161/CIRCULATIONAHA.112.132159)

35 Gray SP, Di Marco E, Kennedy K, Chew P, Okabe J, El-Osta A, Calkin AC, Biessen EAL, Touyz RM, Cooper ME, et al. Reactive oxygen species can provide atheroprotection via NOX4-dependent inhibition of inflammation and vascular remodeling. Arteriosclerosis, Thrombosis, and Vascular Biology 201636 295-307. (https://doi. org/10.1161/ATVBAHA.115.307012)

36 Mollnau H, Wendt M, Szöcs K, Lassègue B, Schulz E, Oelze M, Li H, Bodenschatz M, August M, Kleschyov AL, et al. Effects of angiotensin II infusion on the expression and function of NAD(P) $\mathrm{H}$ oxidase and components of nitric oxide/cGMP signaling. Circulation Research 200290 E58-E65. (https://doi.org/10.1161/01. RES.0000012569.55432.02)

37 Bouabout G, Ayme-Dietrich E, Jacob H, Champy M, Birling M, Pavlovic G, Madeira L, Fertak LE, Petit-Demoulière B, Sorg T, et al. Nox4 genetic inhibition in experimental hypertension and metabolic syndrome. Archives of Cardiovascular Diseases 2018111 41-52. (https://doi.org/10.1016/j.acvd.2017.03.011)

38 Craige SM, Chen K, Pei Y, Li C, Huang X, Chen; C, Shibata R, Sato K, Walsh K \& Keaney JF. NADPH oxidase 4 promotes endothelial angiogenesis through endothelial nitric oxide synthase activation. Circulation $2011 \mathbf{1 2 4}$ 731-740. (https://doi.org/10.1161/ CIRCULATIONAHA.111.030775)

39 Kleinschnitz C, Grund H, Wingler K, Armitage ME, Jones E, Mittal M, Barit D, Schwarz T, Geis C, Kraft P, et al. Post-stroke inhibition of induced NADPH oxidase type 4 prevents oxidative stress and neurodegeneration. PLoS Biology 2010 8. (https://doi.org/10.1371/ journal.pbio.1000479)

40 Schroder K, Zhang M, Benkhoff S, Mieth A, Pliquett R, Kosowski J, Kruse C, Luedike P, Michaelis UR, Weissmann N, et al. Nox4 is a protective reactive oxygen species generating vascular NADPH oxidase. Circulation Research 2012110 1217-1225. (https://doi org/10.1161/CIRCRESAHA.112.267054)

41 Sorescu D, Weiss D, Lassègue B, Clempus RE, Szöcs K, Sorescu GP, Valppu L, Quinn MT, Lambeth JD, Vega JD, et al. Superoxide production and expression of Nox family proteins in human atherosclerosis. Circulation 2002105 1429-1435. (https://doi. org/10.1161/01.cir.0000012917.74432.66)

42 Ellmark SHM, Dusting G, Ngtangfui M, Guzzopernell N \& Drummond G. The contribution of Nox4 to NADPH oxidase activity 
in mouse vascular smooth muscle. Cardiovascular Research 200565 495-504. (https://doi.org/10.1016/j.cardiores.2004.10.026)

$43 \mathrm{Xu}$ S, Chamseddine AH, Carrell S \& Miller FJ. Nox4 NADPH oxidase contributes to smooth muscle cell phenotypes associated with unstable atherosclerotic plaques. Redox Biology 20142 642-650. (https://doi.org/10.1016/j.redox.2014.04.004)

44 Tong X, Khandelwal AR, Wu X, Xu Z, Yu W, Chen C, Zhao W, Yang J, Qin Z, Weisbrod RM, et al. Pro-atherogenic role of smooth muscle Nox4-based NADPH oxidase. Journal of Molecular and Cellular Cardiology 201692 30-40. (https://doi.org/10.1016/j. yjmcc.2016.01.020)

45 Lozhkin A, Vendrov AE, Pan H, Wickline SA, Madamanchi NR \& Runge MS. NADPH oxidase 4 regulates vascular inflammation in aging and atherosclerosis. Journal of Molecular and Cellular Cardiology 2017102 10-21. (https://doi.org/10.1016/j. yjmcc.2016.12.004)

46 Chen F, Haigh S, Barman S \& Fulton DJR. From form to function: the role of Nox4 in the cardiovascular system. Frontiers in Physiology 2012 3 412. (https://doi.org/10.3389/fphys.2012.00412)

47 Touyz RM \& Montezano AC. Vascular Nox4: a multifarious NADPH oxidase. Circulation Research 2012110 1159-1161. (https://doi. org/10.1161/CIRCRESAHA.112.269068)

48 Lee CF, Qiao M, Schröder K, Zhao Q \& Asmis R. Nox4 is a novel inducible source of reactive oxygen species in monocytes and macrophages and mediates oxidized low density lipoprotein-induced macrophage death. Circulation Research 2010106 1489-1497. (https://doi.org/10.1161/CIRCRESAHA.109.215392)

49 Di Marco E, Gray SP, Kennedy K, Szyndralewiez C, Lyle AN, Lassègue B, Griendling KK, Cooper ME, Schmidt HHHW \& JandeleitDahm KAM. NOX4-derived reactive oxygen species limit fibrosis and inhibit proliferation of vascular smooth muscle cells in diabetic atherosclerosis. Free Radical Biology and Medicine 201697 556-567. (https://doi.org/10.1016/j.freeradbiomed.2016.07.013)

$50 \mathrm{Hu}$ P, Wu X, Khandelwal AR, Yu W, Xu Z, Chen L, Yang J, Weisbrod RM, Lee KSS, Seta F, et al. Endothelial Nox4-based NADPH oxidase regulates atherosclerosis via soluble epoxide hydrolase. Biochimica et Biophysica Acta 20171863 1382-1391. (https://doi. org/10.1016/j.bbadis.2017.02.004)

51 Vallet P, Charnay Y, Steger K, Ogier-Denis E, Kovari E, Herrmann F, Michel J-P \& Szanto I. Neuronal expression of the NADPH oxidase NOX4, and its regulation in mouse experimental brain ischemia. Neuroscience 2005132 233-238. (https://doi.org/10.1016/j. neuroscience.2004.12.038)

52 Nisbet RE, Graves AS, Kleinhenz DJ, Rupnow HL, Reed AL, Fan TM, Mitchell PO, Sutliff RL \& Hart CM. The role of NADPH oxidase in chronic intermittent hypoxia-induced pulmonary hypertension in mice. American Journal of Respiratory Cell and Molecular Biology 2009 40 601-609. (https://doi.org/10.1165/2008-0145OC)

53 McCann SK, Dusting GJ \& Roulston CL. Early increase of Nox4 NADPH oxidase and superoxide generation following endothelin-1induced stroke in conscious rats. Journal of Neuroscience Research 2008 86 2524-2534. (https://doi.org/10.1002/jnr.21700)
54 Arimura K, Ago T, Kuroda J, Ishitsuka K, Nishimura A, Sugimori H, Kamouchi M, Sasaki T \& Kitazono T. Role of NADPH oxidase 4 in brain endothelial cells after ichemic stroke. Stroke 201243 A2514.

55 Murray TVA, Smyrnias I, Schnelle M, Mistry RK, Zhang M, Beretta M, Martin D, Anilkumar N, de Silva SM, Shah AM, et al. Redox regulation of cardiomyocyte cell cycling via an ERK1/2 and c-Mycdependent activation of cyclin D2 transcription. Journal of Molecular and Cellular Cardiology 201579 54-68. (https://doi.org/10.1016/j. yjmcc.2014.10.017)

56 Pedruzzi E, Guichard C, Ollivier V, Driss F, Fay M, Prunet C, Marie JC, Pouzet C, Samadi M, Elbim C, et al. NAD(P)H oxidase Nox-4 mediates 7-ketocholesterol-induced endoplasmic reticulum stress and apoptosis in human aortic smooth muscle cells. Molecular and Cellular Biology 200424 10703-10717. (https://doi.org/10.1128/ MCB.24.24.10703-10717.2004)

57 Djordjevic T, BelAiba RS, Bonello S, Pfeilschifter J, Hess J \& Görlach A. Human urotensin II is a novel activator of NADPH oxidase in human pulmonary artery smooth muscle cells. Arteriosclerosis, Thrombosis, and Vascular Biology 200525 519-525. (https://doi.org/10.1161/01.ATV.0000154279.98244.eb)

58 Wu RF, Ma Z, Myers DP \& Terada LS. HIV-1 Tat activates dual Nox pathways leading to independent activation of ERK and JNK MAP kinases. Journal of Biological Chemistry 2007282 37412-37419. (https://doi.org/10.1074/jbc.M704481200)

59 Anilkumar N, Weber R, Zhang M, Brewer A \& Shah AM. Nox4 and Nox2 NADPH oxidases mediate distinct cellular redox signaling responses to agonist stimulation. Arteriosclerosis, Thrombosis, and Vascular Biology 200828 1347-1354. (https://doi.org/10.1161/ ATVBAHA.108.164277)

60 Hancock M, Hafstad AD, Nabeebaccus AA, Catibog N, Logan A, Smyrnias I, Hansen SS, Lanner J, Schröder K, Murphy MP, et al. Myocardial NADPH oxidase- 4 regulates the physiological response to acute exercise. eLife 20187 e41044. (https://doi.org/10.7554/ eLife.41044)

61 Shiojima I. Disruption of coordinated cardiac hypertrophy and angiogenesis contributes to the transition to heart failure. Journal of Clinical Investigation 2005115 2108-2118. (https://doi.org/10.1172/ JCI24682)

62 Sano M, Minamino T, Toko H, Miyauchi H, Orimo M, Qin Y, Akazawa H, Tateno K, Kayama Y, Harada M, et al. p53-induced inhibition of Hif-1 causes cardiac dysfunction during pressure overload. Nature 2007446 444-448. (https://doi.org/10.1038/nature05602)

63 Nabeebaccus AA, Zoccarato A, Hafstad AD, Santos CXC, Aasum E, Brewer AC, Zhang M, Beretta M, Yin X, West JA, et al. Nox4 reprograms cardiac substrate metabolism via protein O-GlcNAcylation to enhance stress adaptation. JCI Insight 20172 96184. (https://doi.org/10.1172/jci.insight.96184)

64 Mongue-Din H, Patel AS, Looi YH, Grieve DJ, Anilkumar N, Sirker A Dong X, Brewer AC, Zhang M, Smith A, et al. NADPH Oxidase-4 driven cardiac macrophage polarization protects against myocardial infarction-induced remodeling. JACC: Basic to Translational Science 20172 688-698. (https://doi.org/10.1016/j.jacbts.2017.06.006)

Received in final form 6 June 2019

Accepted 11 July 2019

Accepted Preprint published online 11 July 2019 https://vb.bioscientifica.com

https://doi.org/10.1530/VB-19-0014
(C) 2019 The authors Published by Bioscientifica Ltd

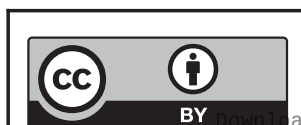

This work is licensed under a Creative Commons Attribution 4.0 International License. 